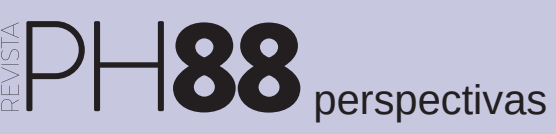

a debate La eficiencia energética y la edificación histórica | coordinan Mónica López Sánchez, Ana Yáñez Vega

\title{
Salvemos nuestros centros históricos de la ruina, caminemos hacia un patrimonio sostenible
}

María López Zambrano | cofundadora de Eficiencia y Patrimonio, doctoranda en la Universidad de Sevilla

URL de la contribución <www.iaph.es/revistaph/index.php/revistaph/article/view/3649>

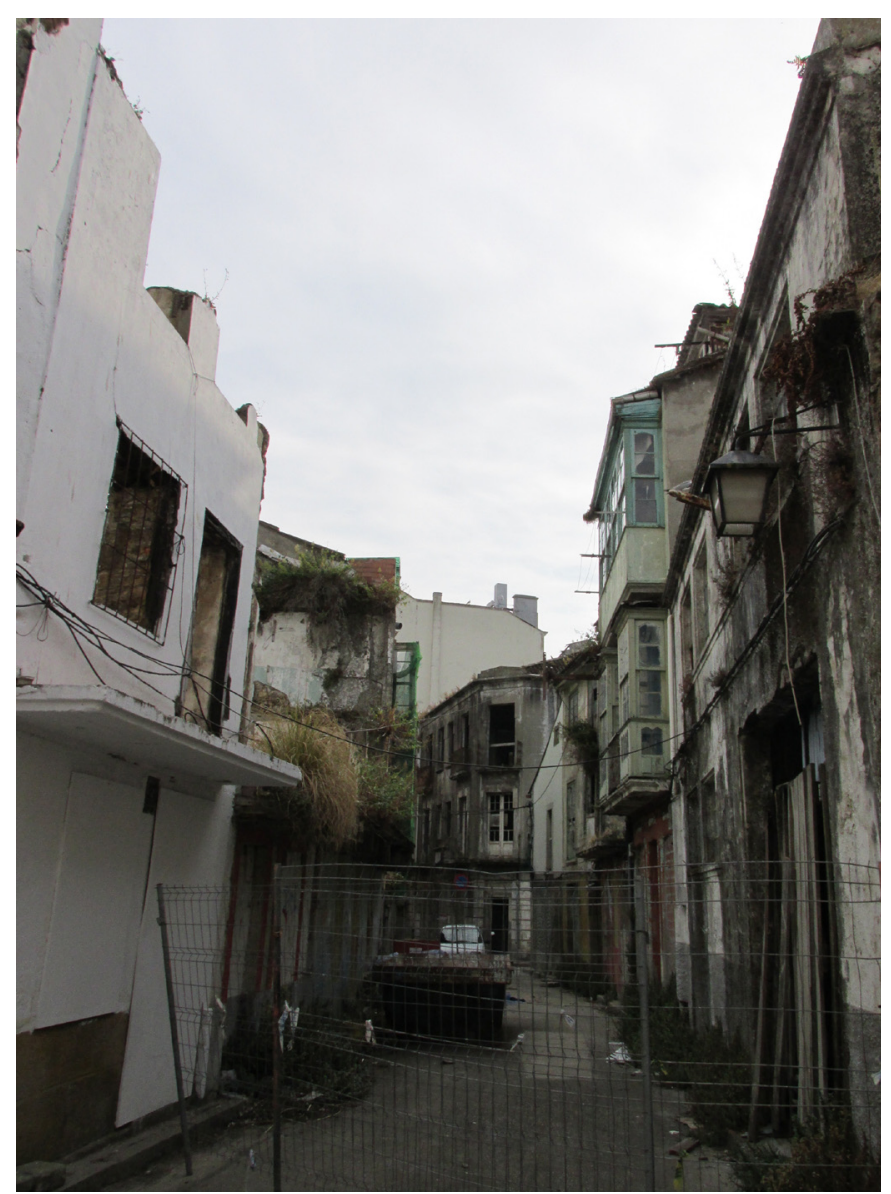

Ferrol Vello | foto David Blanca Esnaola

¿Es compatible la eficiencia energética con la integridad de los conjuntos históricos? Y a continuación, observemos la primera imagen que les muestro como las que aparecen en las cajetillas de tabaco de órganos dañados. La respuesta a esta pregunta invita a varias reflexiones. La imagen que observan no es un sitio ajeno o lejano; es España y es el centro histórico de Ferrol, lo que se llama Ferrol Vello. Si miramos detenidamente, les diré que hasta hace pocos años la gente vivía en estas casas. Hoy hay calles cortadas porque prácticamente todas las viviendas están en peligro de ruina. ¿Y qué tiene que ver esto con la eficiencia energética? En mi opinión, mucho. Aún hay casas en este barrio que están habitadas, muchas de ellas porque sus moradores han hecho el esfuerzo de adaptarse o adaptarlas, como es el caso de la segunda imagen que incluyo en este comentario. Esto no es algo que ocurra sólo en Ferrol; sucede en muchos lugares tanto de España como de otros países. Nuestro modo de vida y necesidades ya no son las mismas que las de hace 100 años y por tanto los usos o la configuración de los hogares tampoco. Ya no necesitamos unas ventanas pequeñas, para evitar que entre o se escape el calor; ahora preferimos grandes ventanas y lo contrarrestamos con calefacción o aire acondicionado. Tenemos ascensores o queremos tener el cuarto de baño dentro de casa. Si un sitio nuevo me lo ofrece, no voy a gastar dinero en otro que posea menos comodidades. Y ésta es una de las claves, el confort.

Por otro lado, se ha fomentado una política de protección de los centros históricos por parte de las administraciones públicas demasiado restrictiva a veces, en la que los propietarios encuentran más un problema que una solución, y además tampoco se les ayuda al mantenimiento. Esto provoca en muchos casos dejar que el edificio muera, para después vender el solar y construir un edificio nuevo en pleno centro, lo que conlleva la pérdida de centros históricos casi en su totalidad. Si el patrimonio no es sostenible en todos los sentidos, se acaba perdiendo.

Por lo tanto, muchos centros históricos permanecen al margen de la mejora de la eficiencia energética, cuando de algún modo podría suponer su salvación. Parece complicado, pero no lo es tanto; sí que requiere implica- 
ción y conocimientos. En este sentido, los profesionales del patrimonio histórico tienen un papel importante en la incorporación de estas medidas, así como profesionales del mundo de la construcción y la ingeniería.

Actualmente existe la tecnología para llevarlo a cabo, muchas veces, el propio edificio ya lo trae incorporado, son las llamadas estrategias pasivas. Se trata de las bases de la arquitectura bioclimática (NEILA GONZÁLEZ, 2004) o Passivhaus, algo que parece muy moderno, pero que nuestros ancestros conocían a la perfección y muchas veces al hacer las rehabilitaciones o reformas, por falta de conocimiento, se bloquean o destruyen, haciendo que el edificio ya no funcione. Por poner algún ejemplo, el techar patios interiores, chapar algunas fachadas, a veces talar árboles de hoja caduca en la orientación sur o cambiar el color de los paramentos exteriores. También existen las estrategias Ilamadas activas, que son lo que comúnmente conocemos como la implementación de instalaciones o servicios que necesitan ser activados de manera mecánica o por otros medios, donde entrarían la domótica o la inmótica, sensores de iluminación inteligente, etcétera. Además, si hubiera voluntad por parte de las administraciones públicas, existe la posibilidad de hacer planes de regeneración a nivel de barrios completos, en los que podrían establecerse centrales de generación de energías renovables que suministrasen la energía a estos edificios sin tener que instalarlos en el propio edificio protegido. Por poner un ejemplo, algo parecido ya se está poniendo en marcha en Móstoles, es lo que se llama District Heating. Otro aspecto importante, teniendo en cuenta que la tecnología avanza rápidamente, es primar siempre la incorporación de medidas reversibles, de tal forma que cuando queden obsoletas podamos remplazarlas por otras nuevas sin dañar al edificio. También es relevante la innovación en la adaptación de productos y sistemas existentes a los edificios históricos.

Algo que tampoco ha favorecido mucho la rehabilitación energética en centros históricos ha sido excluirlos de la mayoría de las acciones normativas que se están desarrollando, derivadas de las directivas europeas sobre efi-

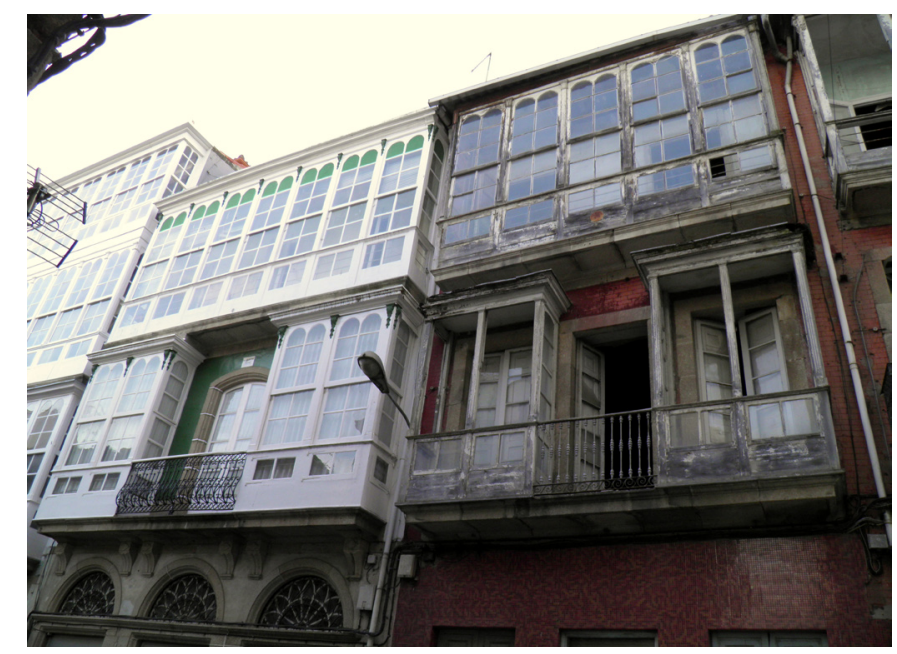

Ferrol Vello | foto David Blanca Esnaola

ciencia energética de edificios (DECRETO 235, 2013), ya que al no estar obligados no se les tiene en cuenta. Por esta razón, son pocos los sitios en España en los que se han empezado a aplicar estas medidas en edificios históricos, por lo que sería conveniente que se impulsaran proyectos de innovación e investigación que permitieran poder hacer posibles estas mejoras de eficiencia energética y además posibilitar la monitorización y cuantificación de las medidas incorporadas para poder hacer políticas y estrategias basándonos en experiencias existentes.

Como conclusión final, debemos mirar a nuestros edificios protegidos. Muchos de ellos incorporan diversas capas de diferentes estilos históricos en los que sus moradores se adaptaban a las mejoras tecnológicas de la época y hoy también forman parte de su historia. Por lo tanto, el edificio que no se adapta, que no es sostenible desde el punto económico, energético o desde el confort, está destinado a desaparecer. Tenemos la oportunidad para hacerlo bien, desde el conocimiento y la tecnología. Es nuestra responsabilidad poner los medios para que no se haga de cualquier manera, que existan equipos multidisciplinares que aborden los proyectos $\mathrm{y}$, en especial, la concienciación a todos los niveles de que se trata de algo realmente importante. Es la única manera de que podamos proteger nuestro patrimonio de la ruina. 
_a debate La eficiencia energética y la edificación histórica | coordinan Mónica López Sánchez, Ana Yáñez Vega

\section{BIBLIOGRAFÍA}

- DECRETO 235/2013, de 5 de abril, por el que se aprueba el procedimiento básico para la certificación de la eficiencia energética de los edificios. Boletín Oficial del Estado, n. ${ }^{\circ} 89$, de 13 de abril de 2013

- DIRECTIVA 2012/27/UE del Parlamento Europeo y del Consejo de 25 de octubre de 2012 relativa a la eficiencia energética, por la que se modifican las Directivas 2009/125/CE y 2010/30/UE, y por la que se derogan las Directivas 2004/8/ CE y 2006/32/CE. Diario Oficial de la Unión Europea del 14 de noviembre de 2012

- NEILA GONZÁLEZ, F. J. (2004) Arquitectura bioclimática en un entorno sostenible. Madrid: Munilla-Lería, 2004 [Serie Arquitectura y tecnología, 4]

- RESOLUCIÓN de 9 de septiembre de 2013, del Instituto para la Diversificación y Ahorro de la Energía, complementaria de la de 25 de junio de 2013, de Consejo de Administración, por la que se establecen las bases reguladoras y convocatoria del programa de ayudas para la rehabilitación energética de edificios existentes del sector residencial. Boletín Oficial del Estado, n. ${ }^{\circ} 244$ del 11 de octubre de 2013 